\title{
The neccesity of an anti-fibrotic coctail instead of a drug only
}

\author{
Akif Altinbas* \\ Karatay Medical Faculty, Medicana Konya Hospital, Gastroenterology Clinic, Konya, Turkey
}

Removal of the causes of liver injury by effective anti-viral medications against hepatits $B$ virüs (HBV) or hepatits $\mathrm{C}$ virüs (HCV) infections or by weight reduction with life style modification and/ or bariatric surgery were all recently determined as effective ways to prevent liver fibrosis $[1,2]$. However, fast one fourth of HBV infected patients under HBV therapies have not shown any improvement in terms of underlying liver fibrosis. Among a sub-group of HCV infected patients, HCV cure has not eleminate the risk of hepatocarcinogenesis though [3].

In the recent years, a huge number of molecular targets were defined for anti-fibrotic drug development $[4,5]$. What we have learned from the studies addressing wide variety new targets, liver fibrosis is a complex process that can be basicly include three main steps: Initiation, progressin and regression. The researchers should take into account that all these steps exist at any time point after the liver injury takes places and are feeding each other through different cytokins [6]. Only the balance between these steps may vary patient to patient, disease to disease or the stage of the fibrosis or severity of the underlying liver injury. Thus, targeting only one point of this complicated process may or can not be the the real solution we have been looking for. Perhaps, that's the reason, why there is no single agent that approved for this use of purpose. Inspite of the success seen in animal liver fibrosis models, a couple of recently developed molecules were failed during phase 3 clinical trials [7]. Or at least they have not supported the hope we have had.

The first one has almost dropped off the pipeline, since the phase 3 clinical trials have revealed no improvement in liver fibrosis $[7,8]$. Even though the importance of targeting lysiloxidase like-2 (LOXL-2) enzyme was already shown in animal models to reduce liver fibrosis by blocking LOXL-2 which stabilizes the linkage between the collagen and elastin fibers to increase the stiffness of liver, the human studies have all failed recently. The first clinical trials of the second target, chemokine ligand 2 (CCL2) which plays important role in recruiting the circulating monocytes in to the liver have not supported our excitements that has arisen based on data obtained from animal models $[9,10]$.

Besides focusing on why these molecules are not the successors so far, I would like to take attention another point of view: The complexity of liver fibrosis. As mentioned above, it is not surprized to see all the steps of liver fibrosis at any time point in every single patient. Therefore, I would rather continue my critics with the term of "anti-fibrotic coctail" instead of anti-fibrotic drug alone.

This anti-fibrotic coctail may or must consist of at least two different products targeting different points of liver fibrogenesis: The first is targeting CCL-2- the cytokine that is mainly responsible for the differentiation of initiation to progression steps of liver fibrosis; and the second is targeting LOXL-2- the enzyme that is specifically responsible for progression of liver fibrosis. Or some other products targeting macrophage polarization or inducing apoptosis of hepatic stellat cells could be further added in to this coctail. The role of some other new targets like NOX1/ NOX4-to decrease hepatocyte apoptosis which takes role especially in initiation step or $\alpha \beta 1$ and $\alpha \beta 6$ to stop further hepatic stellat cell activation appears during advanced liver fibrosis progression- are obvious as well [11-13].

In conclusion, there is no doubt the importance of removing the main cause leading liver injury and then fibrosis. However, due to the complexity of liver fibrosis, we need an anti-fibrotic coctail targeting different points of liver fibrosis at same time to stop or regress it instead of an anti-fibrotic drug alone.

\section{References}

1. Schuppan D, Ashfaq-Khan M, Yang AT, Kim YO (2018) Liver fibrosis: Direct antifibrotic agents and targeted therapies. Matrix Biol. 68-69:435-451. [Crossref]

2. Altinbas A, Sowa JP, Hasenberg T, Canbay A (2015) The diagnosis and treatment of non-alcoholic fatty liver disease. Minerva Gastroenterol Dietol 61: 159-169. [Crossref]

3. Li DK, Chung RT (2015) Impact of hepatitis C virus eradication on hepatocellular carcinogenesis. Cancer. 121: 2874-2882. [Crossref]

4. Higashi T, Friedman SL, Hoshida Y (2017) Hepatic stellate cells as key target in liver fibrosis. Adv Drug Deliv Rev 121: 27-42. [Crossref]

5. Altinbas A, Holmes JA, Salloum S, Lidofsky A, Alatrakchi N, et al. (2017) Comparative evaluation of circulating LOXL-2 and TNC-C in HCV/HIV, HIV and HCV infected patients, in relation to liver fibrosis severity. AASLD, Octover, 2017, Washington, US

6. Canbay A, Friedman S, Gores GJ (2004) Apoptosis: the nexus of liver injury and fibrosis. Hepatology 39: 273-278. [Crossref]

7. Altinbas A (2017) A quick overview to the early phase clinical trials of Simtuzumab ${ }^{\circledR}$ : Are we loosing the most promising anti-fibrotic product? Med Hypotheses 108: 159160. [Crossref]

8. Meissner EG, McLaughlin M, Matthews L, Gharib AM, Wood BJ, et al. (2016) Simtuzumab treatment of advanced liver fibrosis in HIV and HCV-infected adults: results of a 6-month open-label safety trial. Liver Int. 36:1783-1792. [Crossref]

9. Krenkel O, Puengel T, Govaere O, Abdallah AT, Mossanen JC, et al. (2018) Therapeutic inhibition of inflammatory monocyte recruitment reduces steatohepatitis and liver fibrosis. Hepatology. 67:1270-1283. [Crossref]

${ }^{\star}$ Correspondence to: Akif Altinbas, Karatay Medical Faculty, Medicana Konya Hospital, Gastroenterology Clinic, Konya, Turkey, E-mail: drakifa@yahoo.com

Key words: liver fibrosis, anti-fibrotic drug, LOXL-2, CCL2, NOX1/ NOX4, integrins

Received: September 12, 2018; Accepted: September 19, 2018; Published: September 25, 2018 
10. Kruger AJ, Fuchs BC, Masia R, Holmes JA, Salloum, et al. (2018) Prolonged cenicriviroc therapy reduces hepatic fibrosis despite steatohepatitis in a diet-induced mouse model of nonalcoholic steatohepatitis. Hepatol Commun. 2: 529-545. [Crossref]

11. Lidofsky A, Holmes JA, Feeney ER, Kruger AJ, Salloum S, et al. (2018) Macrophage Activation Marker Soluble CD163 is a Dynamic Marker of Liver Fibrogenesis in HIV/ HCV Coinfection. J Infect Dis. 218:1394-1403. [Crossef]
12. Lan T, Kisseleva T, Brenner DA (2015) Deficiency of NOX1 or NOX4 Prevents Liver Inflammation and Fibrosis in Mice through Inhibition of Hepatic Stellate Cell Activation. PLoS One. 7:e129743.

13. Torok NJ, Dranoff JA, Schuppan D, Friedman SL (2015) Strategies and endpoints of antifibrotic drug trials: Summary and recommendations from the AASLD Emerging Trends Conference, Chicago, June 2014. Hepatology 62: 627-634. [Crossref]

Copyright: $\odot 2018$ Altinbas A. This is an open-access article distributed under the terms of the Creative Commons Attribution License, which permits unrestricted use, distribution, and reproduction in any medium, provided the original author and source are credited. 